\title{
Uso racional de antimicrobianos y resistencia bacteriana ¿hacia dónde vamos?
}

\author{
Rational use of antimicrobials and bacterial resistance. Where do we go?
}

La resistencia a los antimicrobianos (ATM) actualmente es una de las mayores amenazas para la salud pública mundial, si no tomamos medidas urgentes llegaremos a la denominada "era post antibiótica", donde ningún ATM tendría lugar en el tratamiento y las infecciones serían mortales, sumado a esto la facilidad de desplazamiento de las personas, tanto en el ámbito nacional e internacional, agrava el problema debido a la diseminación de gérmenes resistentes (1). Aunque la resistencia es un fenómeno natural, el uso irracional de ATM tanto en el ser humano, animales y agricultura están acelerando este proceso (2). Las infecciones por gérmenes resistentes pueden afectar a cualquier persona sin importar edad, religión o región donde se encuentre (1). A nivel hospitalario las infecciones asociadas a la atención de salud (IAAS) cada vez se vuelven más difíciles de tratar. La toma de acciones para su contención es urgente y en nosotros está esa responsabilidad.

En el estudio de Núñez AC y col (3), se evaluó los factores asociados a la presentación de infecciones urinarias por Escherichia coli productoras de betalactamasas de espectro extendido (BLEE), encontraron que el sexo masculino, la edad mayor de 45 años y la hospitalización previa fueron los factores más importantes. En un estudio de vigilancia de Fernández D y col (4), en una unidad de cuidados intensivos, se incluyeron 195 cultivos positivos de secreción endotraqueal de pacientes en ventilación mecánica durante un año. Los gérmenes más frecuentemente hallados fueron Acinetobacter sp. (28\%) y Pseudomonas aeruginosa (22\%); la resistencia a meropenem fue de $90 \%$ y $62 \%$, respectivamente y la prevalencia de BLEE para E. coli (85\%) y K. pneumoniae (75\%) no determinaron si estos cultivos eran infectantes. Ambos trabajos presentados en números anteriores de la Revista Médica Herediana muestran la relación de resistencia bacteriana y la hospitalización previa como factor asociado y una prevalencia elevada de gérmenes Gram negativos no fermentadores extremadamente resistentes (XDR) y enterobacterias productoras de BLEE en un hospital de tercer nivel de Lima.

Los ATM forman parte de los fármacos más comúnmente prescritos en el mundo. Si bien éstos pueden salvar muchas vidas, el usarlos de una manera irracional no sólo encarece los servicios de salud, sino que incrementa la aparición de efectos adversos, interacciones entre drogas y la posibilidad de selección de bacterias resistentes a dichos fármacos. Son pocos los nuevos fármacos antimicrobianos que se desarrollan en la actualidad, de familias ya conocidas por lo cual la posibilidad de compartir mecanismos de resistencia está presente, se necesitan urgentemente nuevos antibióticos (5).

Se estima que unas 700,000 muertes a nivel mundial serán atribuibles a infecciones causadas por organismos resistentes a los antibióticos, y se espera que llegue a 10 millones/año para el 2050; también que la mortalidad por infecciones, en las cuales la resistencia a antimicrobianos es un factor, podría resultar en gastos que ascienden entre 60 y 100 trillones de dólares (6).

Las IAAS que involucran gérmenes multirresistentes como consecuencia del uso irracional de ATM, representan uno de los mayores problemas sanitarios que enfrentan las instituciones prestadoras de salud tanto del sistema privado como público y aquejan de igual manera a países desarrollados como a países en vías de desarrollo.

Frente a tal situación, La Organización Mundial de la Salud (OMS), en un reporte del año 1985, estableció que "el uso racional de medicamentos requiere que el paciente reciba la medicación apropiada a su necesidad clínica en las dosis correspondientes con sus requerimientos individuales, por un periodo adecuado de tiempo y al menor costo para él y su comunidad" (7). Luego el año 2001 define "el uso apropiado de antimicrobianos como el uso costo-efectivo de los antimicrobianos los cuales maximiza su uso terapéutico, mientras minimiza tanto los efectos tóxicos de la droga como el desarrollo de resistencia” (8). 
En mayo del 2015, la Asamblea Mundial de la Salud aprobó un plan de acción mundial sobre la resistencia a los antimicrobianos e insta a los países miembros a desarrollar planes de acción sobre resistencia. El plan contiene cinco objetivos estratégicos: 1) Mejorar la sensibilización y los conocimientos en materia de resistencia a los antimicrobianos; 2) reforzar la vigilancia y la investigación; 3) reducir la incidencia de las infecciones; 4) optimizar el uso de medicamentos antimicrobianos y 5) asegurar que se realicen inversiones sostenibles en la lucha contra la resistencia a los antimicrobianos (1).

En nuestro país, la Norma técnica de prevención y control de infecciones intrahospitalarias del Ministerio de Salud, indica que los responsables de asumir este rol en la política de URA en el hospital son los comités de IAAS y farmacoterapéutico, que deben clasificar los antimicrobianos en grupos controlados y no controlados, definir el nivel de autorización y uso de cada uno de estos grupos (9). Recientemente, en base a las acciones sugeridas por OMS se ha desarrollado el Plan nacional para enfrentar la resistencia bacteriana 2017 - 2021 (10).

En las últimas décadas, se ha logrado demostrar que el uso racional de antimicrobianos (URA) disminuye la presión selectiva favoreciendo la prevención de resistencia antimicrobiana. Una forma de realizar URA es la implementación de programas de optimización de antimicrobianos (PROA), basados en políticas restrictivas y no restrictivas, tales como la autorización de uso de ciertos ATM, educación permanente, desarrollo de guías de manejo, sumados a vigilancia de IAAS los cuales deben adaptarse y estar orientados a satisfacer las necesidades de cada establecimiento de salud (2). Estos programas se vienen implementado de manera aislada en algunos hospitales del país, los cuales para su funcionamiento requieren apoyo de la gestión y estar incluidos en los planes hospitalarios.

¿Cómo imaginar el mundo médico sin antimicrobianos efectivos? Estamos en el proceso de aprender a vivir con los niveles actuales de resistencia bacteriana. Si el problema empeora o se vuelve inmanejable, de nuestras acciones dependerá las medidas para su contención, debemos buscar nuevas opciones de tratamiento, pero al momento el uso racional de antimicrobianos es el elemento crítico para evitar un empeoramiento de la resistencia. Es necesario que cambiemos la forma de prescribir y realicemos uso racional de antimicrobianos como obligación. Si no cambiamos modificando nuestra conducta, ¿quién lo hará?

Eddie Angles ${ }^{1, \mathrm{a} ; 2, \mathrm{~b}}$

\section{REFERENCIAS BIBLIOGRÁFICAS}

1. WHO | Global action plan on AMR [Internet]. WHO. [citado 27 de diciembre de 2017]. Disponible en: http://www.who.int/antimicrobial-resistance/globalaction-plan/en/

2. MacDougall C, Polk RE. Antimicrobial stewardship programs in health care systems. Clin Microbiol Rev. $2005 ; 18(4): 638-56$

3. Calle A, Colqui KA, Rivera DA, Cieza JA. Factores asociados a la presentación de infecciones urinarias por Escherichia coli productoras de betalactamasas de espectro extendido. Rev Med Hered. 2017; 28(3):142-149.

4. Fernández D, García C, Zegarra J, Granados L. Susceptibilidad antimicrobiana en aislamientos de secreción endotraqueal en la unidad de cuidados intensivos de un hospital nacional de Lima, 2016. Rev Med Hered. 2017; 28(4):236-241.

5. Draenert R, Seybold U, Grützner E, Bogner JR. Novel antibiotics: are we still in the pre-postantibiotic era? Infection. 2015; 43(2):145-51.
6. Allcock S, Young EH, Holmes M, Gurdasani D, Dougan G, Sandhu MS, et al. Antimicrobial resistance in human populations: challenges and opportunities. Glob Health Epidemiol Genomics. 2017; 2:e4.

7. WHO. The Rational Use of Drugs. Report of the Conference of Experts. Ginebra. [Internet]. 1985. Disponible en: http://apps.who.int/iris/ bitstream/10665/37403/1/9243561057_spa.pdf

8. WHO. Global Strategy for Containment of Antimicrobial Resistance. Geneva [Internet]. 2001. Disponible en: http://www.who.int/csr/resources/ publications/drugresist/en/EGlobal_Strat.pdf

9. MINSA. Norma técnica de prevención y control de infecciones Intrahospitalarias, Dirección general de salud de las personas, Dirección ejecutiva de Servicios de salud, NT No 020 MINSA/DGSP V.01 Ministerio de Salud - PERU. 2004.

10. Plan Nacional - El portal de resistencia a los antimicrobianos [Internet]. [citado 27 de diciembre de 2017]. Disponible en: http://antimicrobianos.ins. gob.pe/plan-nacional

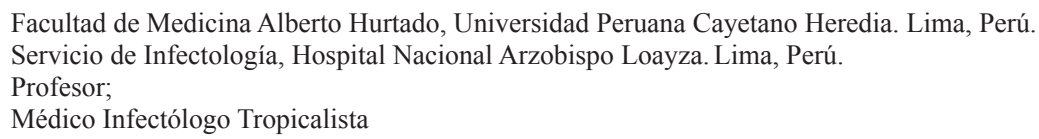

